\title{
Metachronous breast neoplasms: squamous cell carcinoma and lobular carcinoma in situ within a fibroadenoma
}

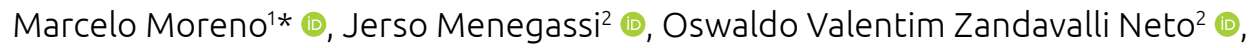 \\ Maiane Maria Pauletto ${ }^{3}$ (), Franciele Meurer $^{3}$ (i)
}

\section{ABSTRACT}

Breast squamous cell carcinoma are rare, occurring in less than $0.1 \%$ of all breast carcinomas. This report describes the oncological conduct performed on a patient with a triple negative squamous cell carcinoma in the upper outer quadrant of the right breast. The same patient presented a lobular carcinoma in situ within a fibroadenoma of the contralateral breast, during the follow up period. The association of these two diseases in the same patient has not yet been described in the literature.

KEYWORDS: breast neoplasms; squamous cell carcinoma; lobular carcinoma.

\section{INTRODUCTION}

Breast squamous cell carcinoma (SCC) occurs when more than $90 \%$ of malignant cells are squamous 1 . Furthermore, the neoplasm cannot be related to cutaneous elements of the breast (skin and areola-papillary complex) and no other invasive cellular components can be present, such as ductal cells ${ }^{2,3}$. The first account of this was described in 1908 by Troell $1^{4}$. It is considered to be a rare neoplasm, as it represents less than $0.1 \%$ of breast carcinomas ${ }^{2,5}$. For this reason, the publications about it are based on reports or case series that mostly analyze the form of treatment used and the prognosis ${ }^{5-8}$.

Carcinoma inside a fibroadenoma is also uncommon'. It is believed that ductal or lobular cells, which characterize a carcinoma, could originate within the pre-existing benign lesion, or both coexist from the beginning ${ }^{9,10}$. Behavior, treatment and prognosis depend on whether the carcinoma component is invasive or in situ $u^{11}$.

This article reports on the clinical-histological findings and the treatment of a breast SCC diagnosed in a patient who, during an oncological follow-up, also presented a lobular carcinoma in situ inside a fibroadenoma.

\section{CASE REPORT}

A 58-year-old white woman came to the consultation to investigate a tumor in her right breast, which had appeared a year before.
The patient reported that the lesion started as a palpable lump inside the breast, grew rapidly and had ulcerated 30 days before. She reported that she had been undergoing breast imaging exams since she was 50 years old and that she had not been diagnosed with a previous lesion at that breast site. A physical examination revealed a $6 \times 5.5 \mathrm{~cm}$ tumor mass, circumscribed and associated with a central spontaneous drainage hole of necrotic material located in the upper outer quadrant (UOQ) of the right breast, $3 \mathrm{~cm}$ from the areola papillary complex. On the mammogram, it was possible to observe a mass that had rounded density, illdefined contours and similar dimensions to the findings of the physical examination (Figure 1). On the ultrasound, the lesion was well defined, with heterogeneous echogenicity and defined contours. It measured $5.19 \times 4.09 \mathrm{~cm}$. Fine needle aspiration puncture (FNAB) of the breast lesion was performed, and a cytopathology described findings compatible with malignant neoplasia. Imaging tests were performed for staging (chest and abdomen tomography), and no signs of distant diseases were found. It was recommended that the patient perform a biopsy of a fragment with a thick needle (core biopsy) to define the histology of the lesion. Then, the form of treatment would be proposed. However, because of a personal request, she was referred to surgery as an initial treatment. The patient underwent a right mastectomy and ipsilateral axillary dissection, and the histopathological description

1 Universidade Federal da Fronteira Sul - Chapecó (SC), Brazil.

IInstituto de Patologia do Oeste - Chapecó (SC), Brazil.

${ }^{3}$ Hospital da Pontifícia Universidade Católica de Porto Alegre - Porto Alegre (RS), Brazil.

*Corresponding author: marcelo.moreno@uffs.edu.br

Conflict of interests: nothing to declare.

Funding: none

Received on: 04/13/2020. Accepted on: 06/15/2020. 
was of a well-differentiated SCC, with a skin invasion. Clusters of malignant squamous cells were present in more than $90 \%$ of the examined histological sections. Eighteen axillary lymph nodes were removed, of which, three were affected by the neoplasia (pT4apN1) (Figures 2 and 3). Assessing clinical history, physical examination, histopathological description of the neoplasm, and the fact that the patient had no previous history of SCC diagnosis in another anatomical site, it was considered to be a primary SCC in the mammary gland. The immunohistochemical examination showed negativity for estrogen/progesterone receptors and for HER-2. The patient underwent adjuvant treatment with chemotherapy (cyclophosphamide, methotrexate and 5-fluorouracil) and radiation therapy.

After three years of oncological follow-up, a fibro adenoma associated with a lobular carcinoma in situ was diagnosed in the UOQ of the left breast. The fibroadenoma measured $1.2 \times 0.8 \mathrm{~cm}$. The lobular carcinoma was $0.4 \mathrm{~cm}$ in size and was in the center of the largest lesion. The margins were described to be compromised, as there were more foci of lobular lesion in situ in the adjacent breast parenchyma. The diagnosis of the lesion in situ was also confirmed by immunohistochemistry, which described a negative lesion for E-cadherin. Because of previous surgery on the right breast, and because of her increased risk of developing more breast cancer, the patient opted for a left adenomastectomy with bilateral reconstruction (placement of bilateral retromuscular expanders, which were replaced by breast implants after six months of tissue expansion). Currently, the patient is asymptomatic, and completing 10 years of clinical follow-up and does not have signs of recurrence of the first neoplasia. This report is part of the research carried out with cancer cases diagnosed in western Santa Catarina and was approved by the Research Ethics Committee of the Universidade Comunitária da Região de Chapecó (opinion no. 069/07).

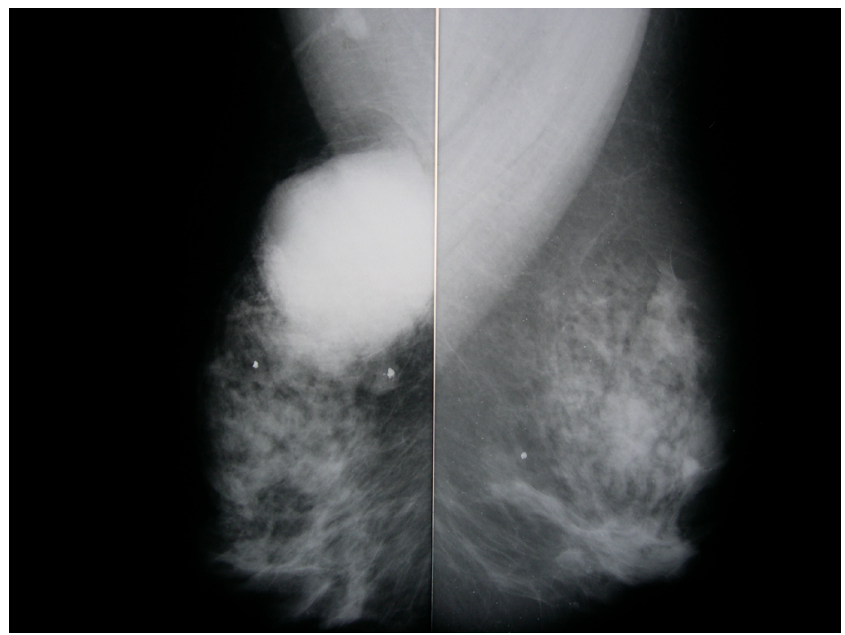

Figure 1. Mammography of the right breast in a lateromedial projection showing a large tumor in the upper outer quadrant of the right breast.

\section{DISCUSSION}

The reported incidence of SCC as a primary breast tumor varies between $0.1 \%$ and $0.4 \%$ in relation to all breast carcinomas ${ }^{12,13}$. This neoplasm has already been described in women aged between 29 and 90 years old, but the diagnosis predominates in patients

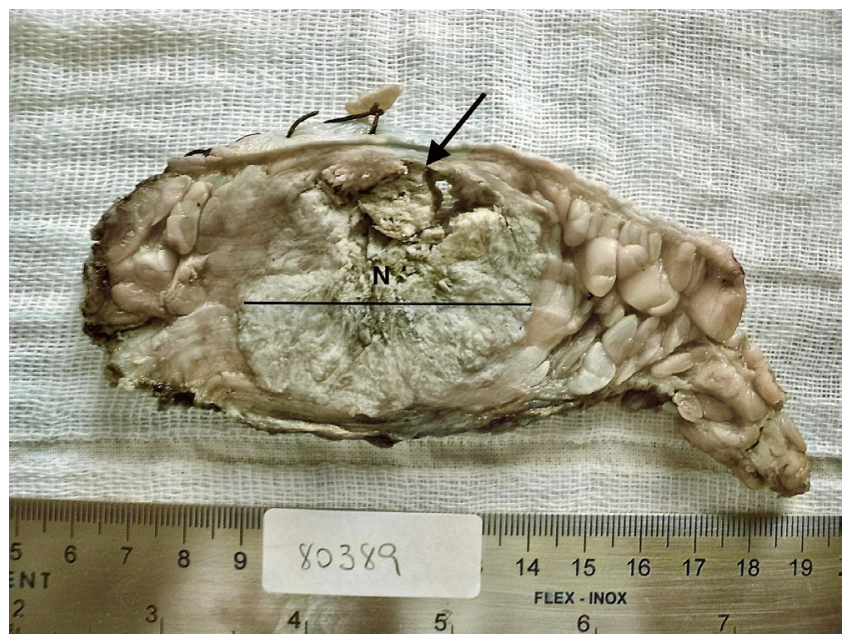

Figure 2. A macroscopic examination of the surgical specimen, with a centralized tumor lesion between the breast tissue, containing a central area with necrosis ( $\mathrm{N}$ ) and a skin extension (arrow).

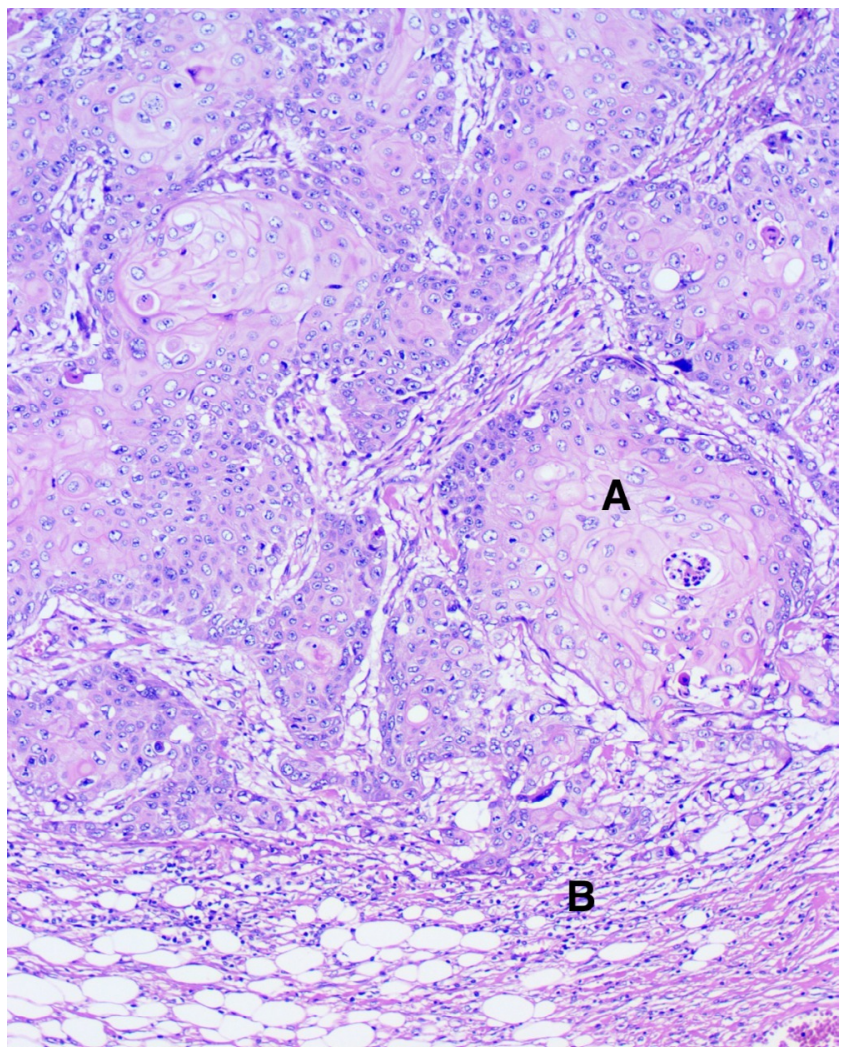

Figure 3. Photomicroscopy of primary breast squamous cell carcinoma (H\&E 200X). (A) Area with a cluster of malignant squamous neoplastic cells; (B) connective tissue of the adjacent breast parenchyma. 
aged 50 to 54 years old ${ }^{13,14}$. They are usually large tumors at the time of the diagnosis (greater than $4 \mathrm{~cm}$ ), due to rapid growth, which can evolve with central necrosis ${ }^{12-14}$. The reported patient was slightly older than the most frequent age group, and had a clinical presentation similar to that documented in the literature, including a rapid increase in tumor size and the presence of central necrosis that evolved to cutaneous fistulization. To define that SCC as the primary cancer of the breast, it is necessary for the predominant cell type to be squamous cells (more than $90 \%$ of the neoplasia area). Furthermore, the lesion cannot have any relation with the overlying skin and there can be no indication of primary SCC in other anatomical sites ${ }^{12}$. The histogenesis of this type of neoplasm has not yet been defined, but it is believed that it may be the result of the evolution of a scaly metaplasia in a previous benign breast lesion ${ }^{13}$. Another possibility is that the SCC originates from an area of squamous metaplasia within an invasive ductal carcinoma ${ }^{7,8,12,14}$. In the case of the patient presented, there was no clinical report or documentation of a previous breast image describing a lesion in the UOQ of the right breast.

There are no specific radiological findings of this neoplasm on mammography exams ${ }^{13,14}$. Ultrasonography may show a nodule with heterogeneous echogenicity that is well defined, or an area with echographic characteristics of a cyst or breast abscess ${ }^{15,16}$. These characteristics were described in the ultrasound examination of the patient's breast lesion reported here.

The main cytological finding in material from FNAB is the presence of malignant squamous cells; and an incisional biopsy is usually necessary for a definitive diagnosis ${ }^{12-15}$. In the case reported, the patient did not want to proceed with further investigation. In view of the clinical aspect of the lesion, she requested to undergo surgical treatment. As a result, there was no histological definition of the neoplasia nor, consequently, the option of neoadjuvant therapy, which made conservative breast surgery impossible.

Usually, primary breast SCCs are neoplasms that do not express estrogen or progesterone receptors ${ }^{12,13}$, and, therefore, hormone therapy is part of the therapeutic arsenal. However, in most cases, there is a positive epidermal growth factor receptor (EGFR), cytokeratin CK5 and CK6, which may explain the high rate of cell proliferation and therefore the poor prognosis ${ }^{4,15}$. The immunohistochemical examination of the neoplasm diagnosed in the present case described a triple-negative neoplasm, which corresponded to that documented in the literature on primary breast SCC. No research was performed on EGFR, CK5 or CK6.

The treatment of breast SCC does not differ from that instituted for other histological types, which may involve surgery, neoadjuvant or adjuvant chemotherapy, and radiotherapy ${ }^{14,16}$.
Radiotherapy plays an important role, considering that most cases have a locally advanced presentation of the disease ${ }^{17}$.

Previous studies indicate that the prevalence of lymph node metastasis varies from $41 \%$ to $47 \%^{7,17,18}$. Patients with lymph node involvement from the neoplasm seem to have a better response to adjuvant chemotherapy compared to those with no involvement ${ }^{18}$. However, surgery is considered the main choice in order to manage the disease. A radical mastectomy is the most commonly used mainly due to the tumor size in the initial presentation ${ }^{19}$.

Clinical progression is generally poor, and the most important prognostic factor is the size of the primary lesion at the time of the diagnosis. Tumors with a diameter greater than $5 \mathrm{~cm}$ are associated with a greater chance of systemic recurrences ${ }^{19}$. Five-year survival ranges from $60 \%$ to $75 \%^{16,19}$.

In addition to the rarity of the first tumor, the patient developed lobular carcinoma in situ in fibroadenoma in the contralateral breast, during the third year of cancer followup. The association between carcinoma and fibroadenoma is also considered to be rare ${ }^{9}$. In a series that evaluated 30 cases with this association, $53.3 \%$ had invasive ductal carcinoma, followed by $23.3 \%$ having ductal carcinoma in situ, $16.7 \%$ having lobular carcinoma in situ and $13.3 \%$ having invasive lobular carcinoma ${ }^{10}$. It is normally diagnosed in women aged between 44 and 47 years old ${ }^{9,10}$. This finding is usually incidental and occurs after surgical removal of a fibradenoma ${ }^{10,11}$. Whatever the type of neoplasm associated with fibroadenoma (in situ or invasive, lobular or ductal), the biological behavior is the same as for carcinomas that originate outside the fibradenoma ${ }^{11}$.

Treatment follows the pattern for non-fibroadenoma-related carcinomas. In the case of carcinoma in situ originating within a fibroadenoma, conservative treatment is recommended. However, because lobular carcinoma in situ is associated with an increased risk of developing breast cancer, a prophylactic mastectomy may be considered (if the patient has clinical criteria or laboratory tests that characterize genetic mutation) ${ }^{9-11}$.

The case presented here has the particularity of primary breast SCC, with a clinical presentation, radiological findings, a histological diagnosis, and an immunohistochemistry with the same characteristics as the cases described in the literature. In the oncological follow-up, it was possible to diagnose the second neoplasia in a period of three years and to carry out complementary surgical treatment. Due to the fact that the patient had previously undergone a right mastectomy due to a rare neoplasm and because she had a new lesion associated with an increased risk of developing another breast cancer, we opted for an adenomastectomy on the left, with immediate reconstruction and a tissue expander, and subsequent prosthesis replacement in both breast sites. 


\section{CONCLUSION}

Primary breast SCC is rare and is associated with a worse prognosis than unspecified breast carcinoma. Lobular carcinoma in situ, originating within a fibroadenoma, is also an uncommon diagnosis. In the case reported, these two neoplasms were diagnosed metachronously, and it was possible to adjust the conduct of each one according to what is recommended in the literature. The patient has survived disease-free for 10 years, despite the fact that the initial stage of SCC is normally related to a worse prognosis. The diagnosis of the second neoplasm was only possible through adequate oncological follow-up.

\section{AUTHORS' CONTRIBUTION}

M.M.: Design, acquisition of funding, investigation, methodology, project administration, supervision, validation, visualization, writing - reviewing and editing.

J.M.: Acquisition of funding, investigation, methodology, writing - reviewing and editing.

O.N.: Acquisition of funding, investigation, methodology, writing - reviewing and editing.

M.P.: Design, acquisition of funding, investigation, methodology, writing - reviewing and editing.

F.M.: Design, acquisition of funding, investigation, methodology, writing - reviewing and editing.

\section{REFERENCES}

1. Schmitt G, Gobbi H. Mama. In: Bogliolo Filho G, editor. Bogliolo Patologia. 9a ed. Rio de Janeiro: Guanabara Koogan; 2016. p. 613-43.

2. Rosen PR. Patologia da mama de Rosen. Philadelphia: Lippincott Williams \& Wilkins; 2017. p. 455-61.

3. Lester SC. A mama. In: Kumar V, Abbas AK, Fausto N, Aster JC, editores. Patologia Bases Patológicas das Doenças. $9^{\mathrm{a}}$ ed. Rio de Janeiro: Elsevier; 2016. p. 1073-103.

4. Troell A. Zwei Falle von Palttenepithelcarcinom. Nord Med Arca. 1908;1:1-11.

5. Behranwala KA, Nasiri N, Abdullah N, Trott PA, Gui GPH. Squamous cell carcinoma of the breast: clinico-pathologic implications and outcome. Eur J Surg Oncol. 2003;29(4):386-9. https://doi.org/10.1053/ejso.2002.1422

6. Gupta C, Malani AK, Weigand RT, Rangineni G. Pure primary squamous cell carcinoma of the breast: A rare presentation and clinicopathologic comparison with usual ductal carcinoma of the breast. Pathol Res Pract. 2006;202(6):465-9. https://doi. org/10.1016/j.prp.2006.01.006

7. Pirot F, Chaltiel D, Ben Lakhdar A, Mathieu MC, Rimareix F, Conversano A. Squamous cell carcinoma of the breast, are there two entities with distinct prognosis? A series of 39 patients. Breast Cancer Res Treat. 2020;180(1):87-95. https:// doi.org/10.1007/s10549-020-05525-5

8. Soliman M. Squamous cell carcinoma of the breast: A retrospective study. Am Surg. 2019;15(5):1057-61. https://doi. org/10.4103/jcrt.jcrt_303_17

9. Saimura M, Koga K, Anan K, Mitsuyama S, Tamiya S. Diagnosis, characteristics, and treatment of breast carcinomas within benign fibroepithelial tumors. Breast Cancer. 2018;25(4):470-8. https://doi.org/10.1007/s12282-018-0847-7

10. Wu Y-T, Chen S-T, Chen C-J, Kuo Y-L, Tseng L-M, Chen D-R, et al. Breast cancer arising within fibroadenoma: collective analysis of case reports in the literature and hints on treatment policy. World J Surg Oncol. 2014;12:335. https://doi.org/10.1186/1477-7819-12-335
11. Limite G, Esposito E, Sollazzo V, Ciancia G, Formisano C, Di Micco R, et al. Lobular intraepithelial neoplasia arising within breast fibroadenoma. BMC Res Notes. 2013;6:267. https://doi. org/10.1186/1756-0500-6-267

12. Honda M, Saji S, Horiguchi S, Suzuki E, Aruga T, Horiguchi $\mathrm{K}$, et al. Clinicopathological analysis of ten patients with metaplastic squamous cell carcinoma of the breast. Surg Today. 2011;41(3):328-32. https://doi.org/10.1007/s00595-009-4276-2

13. Anne N, Sulger E, Pallapothu R. Primary squamous cell carcinoma of the breast: a case report and review of the literature. J Surg Case Rep. 2019;2019(6):182. https://dx.doi. org/10.1093\%2Fjscr\%2Frjz182

14. Murialdo R, Boy D, Musizzano Y, Tixi L, Murelli F, Ballestrero A. Squamous cell carcinoma of the breast: a case report. Cases J. 2009;2:7336. Squamous cell carcinoma of the breast: a case report. Cases Journal.

15. Aparicio I, Martínez A, Hernández G, Hardisson D, De Santiago J. Squamous cell carcinoma of the breast. Eur J Obstet Gyn R B. 2008;137(2):222-6. https://doi.org/10.1016/j.ejogrb.2007.03.021

16. Badge SA, Gangane NM, Shivkumar VB, Sharma SM. Primary squamous cell carcinoma of the breast. Int J Appl Basic Med Res. 2014;4(1):53-5. https://dx.doi.org/10.4103\%2F2229-516X.125697

17. Gupta N, Vashisht R, Nimbran V, Gupta R, Dhingra N, Bhutani A. Primary squamous cell carcinoma of the breast: Case report and management decisions. J Cancer Res Ther. 2012;8(2):323-5. https://doi.org/10.4103/0973-1482.99006

18. Liu J, Yu Y, Sun J, He S, Wang X, Yin J, et al. Clinicopathologic characteristics and prognosis of primary squamous cell carcinoma of the breast. Breast Cancer Res Treat. 2015;149(1):133-40. https://doi.org/10.1007/s10549-014-3224-z

19. Hennessy BT, Krishnamurthy S, Giordano S, Buchholz TA, Kau SW, Valero ZDV, et al. Squamous Cell Carcinoma of the Breast. J Clin Oncology. 2005;23(31):7827-35. https://doi.org/10.1200/ JCO.2004.00.9589 